\title{
Preoperative brain magnetic resonance imaging and postoperative delirium after off-pump coronary artery bypass grafting: a prospective cohort study
}

\section{Imagerie préopératoire par résonance magnétique du cerveau et délirium postopératoire après pontage coronarien à cour battant: une étude prospective de cohorte}

\author{
Hiroki Omiya, MD · Kenji Yoshitani, MD • Naoki Yamada, MD • \\ Yosuke Kubota, MD • Kanae Takahashi, MPH · Junjiro Kobayashi, MD • \\ Yoshihiko Ohnishi, MD
}

Received: 7 May 2014/Accepted: 19 January 2015/Published online: 5 February 2015

(c) Canadian Anesthesiologists' Society 2015

\begin{abstract}
Background Delirium after cardiac surgery is a serious complication, increasing morbidity and mortality. Despite its high expectations, off-pump coronary artery bypass grafting $(O P C A B)$ has largely failed to reduce the incidence of postoperative neurological complications. To further investigate the reasons for this failure, we used perioperative brain magnetic resonance imaging (MRI) to determine the relation between MRI findings and postoperative delirium.

Methods Altogether, 98 patients undergoing elective $O P C A B$ were enrolled in this prospective observational study. Patients underwent brain MRI and magnetic resonance angiography (MRA) before and after surgery to identify cerebral infarction, white matter lesions, and
\end{abstract}

\footnotetext{
Author contributions Hiroki Omiya was involved in patient recruitment and writing the manuscript. Kenji Yoshitani was involved in patient recruitment and data collection. Naoki Yamada was involved in review of the brain magnetic resonance images. Yosuke Kubota was involved in patient recruitment and data collection. Kanae Takahashi was involved in study design and data analysis. Junjiro Kobayashi assisted with editing of the manuscript, particularly for the surgical procedure. Yoshihiko Ohnishi was involved in overall supervision and management of the study.
}

H. Omiya, MD · K. Yoshitani, MD ( $\varangle) \cdot$ Y. Kubota, MD ·

Y. Ohnishi, MD

Department of Anesthesiology, National Cerebral and

Cardiovascular Centre, 5-7-1 Fujishirodai, Suita, Osaka

565-8565, Japan

e-mail: yoshitani.kenji.hp@ncvc.go.jp

N. Yamada, MD

Department of Radiology, National Cerebral and Cardiovascular

Centre, Suita, Osaka, Japan intracranial artery stenosis. Postoperative delirium in the intensive care unit was measured using the delirium rating scale. The relation between postoperative delirium and MRI findings was examined using logistic regression.

Results Magnetic resonance imaging and MRA was completed in 88 (90\%) of the patients. New ischemic lesions were present in seven (7.9\%) patients. Delirium rating scale scores of $0,1-7$, and $\geq 8$ were found in 25 (31\%), 48 (60\%), and seven (9\%) patients, respectively. Multivariate logistic regression analysis revealed that new ischemic lesions (odds ratio [OR] 11.07, 95\% confidence interval [CI]: 1.53 to $80.03 ; P=0.017)$, carotid artery stenosis (OR 7.06, 95\% CI: 1.59 to 31.13; $P=0.010)$, history of myocardial infarction (OR 3.78, 95\% CI: 1.05 to 13.65; $P=0.043)$, and deep subcortical white matter hyperintensity (OR 3.04, 95\% CI: 1.14 to 8.12; $P=0.027$ ) were significantly associated with postoperative delirium. Conclusions Magnetic resonance imaging findings of new cerebral ischemic lesions, carotid stenosis, and deep subcortical white matter hyperintensity correlated significantly with postoperative delirium in patients who had undergone OPCAB surgery.

\footnotetext{
K. Takahashi, MPH

Department of Advanced Medical Technology Development, National Cerebral and Cardiovascular Centre, Suita, Osaka, Japan

J. Kobayashi, MD

Department of Cardiovascular Surgery, National Cerebral and Cardiovascular Centre, Suita, Osaka, Japan
} 


\section{Résumé}

Contexte La survenue d'un délirium après chirurgie cardiaque est une complication grave, augmentant la morbidité et la mortalité. En dépit des fortes attentes, le pontage coronarien à coeur battant $(O P C A B)$ a largement échoué à démontrer qu'il pouvait réduire l'incidence des complications neurologiques postopératoires. Pour approfondir l'étude des raisons de cet échec, nous avons utilisé une imagerie par résonance magnétique (IRM) périopératoire du cerveau pour déterminer la relation entre les constations de l'IRM et le délirium postopératoire.

Méthodes Un ensemble de 98 patients subissant un $O P C A B$ électif a été inclus dans cette étude observationnelle prospective. Les patients ont subi une IRM cérébrale et une angiographie par résonance magnétique (ARM) avant et après l'intervention chirurgicale afin d'identifier un infarctus cérébral, des lésions de la substance blanche et une sténose d'une artère intracrânienne. Le délirium postopératoire a été mesuré dans l'unité de soins intensifs au moyen de l'échelle d'évaluation $d u$ délirium. La relation entre le délirium postopératoire et les constatations de l'IRM a été analysée par régression logistique.

Résultats L'imagerie par résonance magnétique et l'ARM ont été effectuées chez 88 (90\%) patients. De nouvelles lésions ischémiques ont été retrouvées chez sept (7,9\%) patients. Les scores de l'échelle d'évaluation du délirium étaient de 0,1 à 7 , et $\geq 8$ chez, respectivement, 25 (31\%), 48 (60\%), et 7 (9\%) patients. Analyse de régression logistique multifactorielle a révélé que les nouvelles lésions ischémiques (rapport de cotes [RC] 11,07, intervalle de confiance [IC] à $95 \%: 1,53$ à 80,03; $P=0,017)$, une sténose carotidienne $(R C 7,06, I C$ à $95 \%: \quad 1,59$ à 31,$13 ; \quad P=0,010)$, un antécédent d'infarctus du myocarde (RC 3,78, IC à $95 \%$ : 1,05 à 13,65; $P=0,043)$, et une hyperintensité de la substance blanche sous-corticale profonde (RC 3,04, IC à $95 \%: 1,14$ à 8,$12 ; P=0,027)$ étaient significativement associés au délirium postopératoire.

Conclusions La constatation par imagerie cérébrale par résonance magnétique de nouvelles lésions ischémiques cérébrales, d'une sténose carotidienne et d'une hyperintensité de la substance blanche sous-corticale profonde est significativement corrélée au délirium postopératoire chez des patients ayant subi une intervention pour $O P C A B$.

As a result of continuing improvements in surgical techniques and cardiovascular anesthesia, an increasing number of elderly patients with a similarly increasing number of comorbidities are able to safely undergo cardiac surgery. Although mortality after cardiac surgery has decreased, neurologic complications remain an important and widespread issue in an ever-aging surgical population. Delirium, reflecting acute changes in cognition and attention, is common after cardiac surgery, occurring in $9-52 \%$ of patients. ${ }^{1,2}$ In particular, recent studies have revealed that postoperative delirium may have more than transient effects, and can negatively affect long-term morbidity and mortality. ${ }^{1,3-5}$ Therefore, understanding the risks for postoperative delirium is an important consideration for surgeons and anesthesiologists.

Cardiopulmonary bypass (CPB) may result in neurological injury caused by emboli, systemic inflammation, and unpredictable intraprocedural hypoperfusion. ${ }^{6}$ In an attempt to avoid these adverse CPB sequelae, off-pump coronary artery bypass grafting (OPCAB) was introduced during the early 1990s. This technique was expected to reduce postoperative neurological complications, but recent studies largely failed to show any significant benefit. ${ }^{7-9}$

Microembolization has been considered a significant contributor to postoperative delirium. ${ }^{10,11}$ However, relatively few studies have investigated the relation between the brain lesions that would be expected to result from a significant embolic load and postoperative delirium. Indeed, studies of cerebral emboli in conventional on-pump coronary artery bypass surgery (CABG) using transcranial Doppler (TCD) have failed to show any significant association with postoperative delirium. ${ }^{12}$ In regard to OPCAB, however, there are a few reports investigating the relation between cerebral embolia and postoperative delirium. Importantly, not all of the cerebral emboli detected by TCD would be expected to induce a clinically apparent ischemic lesion. Therefore, magnetic resonance diffusion-weighted imaging (DWI) might provide more information about the more subtle ischemic lesions caused by cerebral emboli.

With respect to carotid artery lesions, we previously reported that carotid artery stenosis was significantly associated with postoperative stroke and delirium. ${ }^{13}$ Embolic signals measured using TCD were even observed in patients with asymptomatic carotid artery stenosis, resulting in silent cerebral infarction. ${ }^{14,15}$ Significant atherosclerosis, manifesting as carotid stenosis or ascending aortic plaque, was also associated with delirium after CABG. ${ }^{16}$ Therefore, evaluation of carotid artery stenosis and ascending aortic plaque to identify its relation to both postoperative delirium and new magnetic resonance imaging (MRI)-detectable ischemic lesions may provide important information on the pathophysiology of these neurological abnormalities. 
The principal aim of the present study was to investigate the relation between postoperative delirium and new ischemic lesions detected by MRI-DWI after OPCAB. The impact of magnetic resonance angiographic (MRA) detectable intracranial artery stenoses that could result in cerebral hypoperfusion was also explored. Finally, as recent studies have reported that white matter hyperintensities may predict postoperative delirium with conventional on-pump CABG,${ }^{17-19}$ we assessed whether these white matter lesions were associated with postoperative delirium after OPCAB.

\section{Methods}

\section{Patients}

The institutional review board of our hospital approved this study (September 2008). All participants provided written informed consent prior to enrolment. From February 2009 to July 2011, consecutively consenting patients undergoing elective OPCABG who were more than $20 \mathrm{yr}$ old were enrolled. Exclusion criteria included patients with contraindications to MRI (e.g., claustrophobia or anxiety) or who had psychiatric disease (depression) or Kawasaki's disease.

\section{Brain MRI}

Brain MRI was performed using two 1.5-T systems (MAGNETOM Vision or MAGNETOM Sonata; Siemens Healthcare, Tokyo, Japan). All patients underwent preoperative MRI within three days of surgery, with postoperative MRI being performed within two weeks after removal of the temporary pacing leads. Preoperative MRI was performed using T2-weighted imaging (T2WI) with TR/TE of $5400 / 99 \mathrm{msec}$ or $5400 / 85 \mathrm{msec}$; T2*weighted imaging (T2*WI) with TR/TE of 736/20 msec and a flip angle of $30^{\circ}$; fluid-attenuated inversion recovery (FLAIR) with TR/TE/TI of 9000/105/2400 msec; diffusion-weighted imaging (DWI) with TR/TE of 4000/ $100 \mathrm{msec}$ and $\mathrm{b}$ of $1000 \mathrm{sec} \cdot \mathrm{mm}^{-2}$ and MRA. A slice thickness of $4 \mathrm{~mm}$ with a slice interval of $2 \mathrm{~mm}$ was used for T2WI, T2*WI, FLAIR, and DWI. Postoperative MRI was performed using the same sequences as for preoperative MRI. MRA was not performed postoperatively.

Abnormal lesions were diagnosed as follows. Preoperative cerebral infarction was detected using preoperative FLAIR and DWI. A significant intracranial arterial stenosis was defined as $>50 \%$ stenosis on MRA in one or more of the intracranial carotid, vertebral, basilar, first and second portions of the anterior cerebral, and/or the horizontal portion of the middle cerebral arteries. Using DWI and FLAIR, new postoperative ischemic lesions were defined as cerebral lesions $>2 \mathrm{~mm}$ that were not present before surgery. Minor intracranial bleeding was diagnosed using T2*WI. White matter lesions were defined as periventricular hyperintensity $(\mathrm{PVH})$ and deep subcortical white matter hyperintensity (DSWMH). They were graded (grades 0-3) according to the Fazekas scale: 0, absence; 1, cap of pencil-thin PVH or punctate focal DSWMH; 2, smooth halo PVH or early confluence of focal DSWMH; 3, irregular PVH extending into the deep white matter or large confluent areas of DSWMH. ${ }^{20}$ An experienced neuroradiologist blinded to the patients' preoperative and postoperative clinical status read the MR images. Preoperative carotid artery duplex scanning was performed to assess the severity of the carotid stenosis, which was quantified as present (stenosis $>50 \%$ ) or absent (stenosis $<50 \%)$. $^{21}$ Transesophageal echocardiography was performed in all patients to evaluate the severity of aortic atherosclerosis (using the Katz score). ${ }^{22}$

\section{Delirium assessment}

All patients were assessed for delirium six to $24 \mathrm{hr}$ after extubation by a nurse trained to use the delirium rating scale R98 (DRS-R98). The DRS-R98 is composed of a 16item clinician-rated scale. It include three severity items and three diagnostic items, for a maximum total score of 46 points. $^{23}$ The DRS-R98 divides delirium into three categories based on severity: no delirium (total points 0 ), subclinical delirium (total points 1-7), and delirium (total points $\geq 8)$. $^{24}$

\section{Operative procedure}

All patients underwent standard OPCAB using an aortic "no-touch" technique, avoiding aortic side clamping and manipulation of the ascending artery to minimize the risk of stroke. Vein grafts were anastomosed with an assist device where indicated, using either the Enclose 2 (Novare Surgical Systems, Inc. Cupertino, CA, USA) or the PAS PORT system (Cardiac Inc., Redwood City, CA, USA). Surgical procedures, operative times, and use of anesthetic and narcotics were obtained from the operative record. We selected potential risk factors of postoperative delirium from a review of the literature. Candidate variables included age, body weight, history of smoking, hypertension, hyperlipidemia, heart failure, diabetes, perioperative atrial fibrillation, myocardial infarction, cerebral infarction, chronic obstructive pulmonary disease, chronic kidney disease, duration of the operation and anesthesia, intubation time, and MRI findings. 
Statistical analysis

Our initially planned sample size was based on an expected delirium incidence of $12 \%$ in patients without carotid stenosis. Using a power of $80 \%$, a $5 \%$ two-sided significance level, and a 2.5 ratio of patients with carotid artery stenosis to patients without carotid artery stenosis, with a 2.0 relative risk of delirium in those with carotid stenosis, ${ }^{13}$ our final sample size was estimated to be 370 .

Continuous variables are presented as the mean (SD), and discrete variables are presented as the frequency and percentages. Univariate analysis with the proportional odds model was used to evaluate risk factors for postoperative delirium. The proportional odds ratio (OR) was assumed to be equal between the two groups' comparisons (i.e., DRS score between 0 and 1-7; as well as between 1-7 and $\geq 8$ ) in this model. In addition, we conducted a multivariate analysis that included risk factors with a univariate $P<0.3$. The model was selected by the Akaike's information criterion (AIC), ${ }^{25}$ with low AIC values being preferred. ORs and 95\% confidence intervals (CI) were also determined. Postoperative outcome, length of stay (LOS) in the intensive care unit (ICU), intubation, and hospital LOS were tested between patients with or without delirium using the non-parametric Jonckheere-Terpstr test. $P$ values $<0.05$ (two-sided) were considered to indicate significance. Statistical analyses were performed with SAS version 9.3 (SAS Institute, Cary, NC, USA).

\section{Results}

Because patient recruitment was slower than expected, we ceased enrolment after a convenience sample of 105 eligible patients (Figure). Before the baseline data collection, seven patients were excluded for claustrophobia, anxiety, or refusing informed consent. Ten patients were further excluded from analysis because of either the MRI or carotid artery ultrasonography not being completed. We thus analyzed 88 patients. The patients' preoperative characteristics and intraoperative parameters are shown in Table 1. MRI findings are shown in Table 2. Preoperative MRA revealed intracranial artery lesions in $24(27 \%)$ of the 88 patients. PVH was found in $71(81 \%)$ patients and DSWMH in $76(86 \%)$ patients. Postoperative DWI or FLAIR MRI detected new ischemic lesions in seven (7.9\%) patients. Overall, $25(32 \%), 48(60 \%)$, and seven (8\%) patients had total DRS scores of $0,1-7$, and $\geq 8$, respectively.

Table 3 shows the univariate analysis of factors correlated with postoperative delirium. Older age ( $\geq 70 \mathrm{yr}$ ), preoperative myocardial infarction, new ischemic lesions on MRI, new white matter disease (WMD; i.e., DSWMH or PVH) had a significant association with postoperative delirium. Multivariate analysis demonstrated a significant association

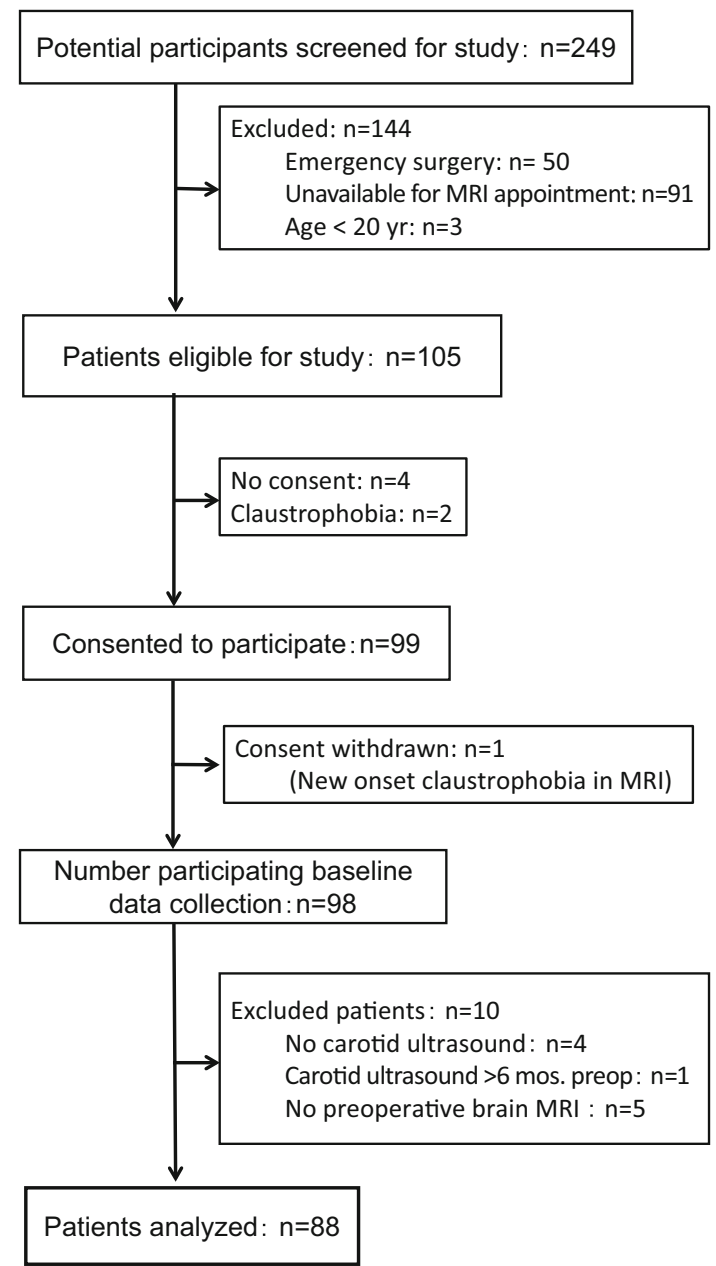

Figure Patient enrolment and outcomes. MRI $=$ magnetic resonance imaging

with new ischemic lesions (OR 11.07, 95\% CI 1.53 to 80.03; $P=0.017$ ), carotid artery stenosis (OR 7.06, 95\% CI 1.59 to $31.31 ; P=0.010)$, myocardial infarction (OR $3.78,95 \%$ CI 1.05 to $13.65 ; P=0.043$ ), and WMD (OR $3.04,95 \% \mathrm{CI}$ 1.14 to $8.12 ; P=0.027$ ) (Table 4 ). As the DRS advanced from 1-7 to $\geq 8$, the ICU LOS was significantly greater in patients with postoperative delirium than in those without delirium (Table 5).

There was no significant association between new ischemic lesions detected by MRI and carotid artery stenosis, cerebral artery stenosis, or the degree (determined by the Katz score) of aortic atherosclerosis. ${ }^{22}$

\section{Discussion}

This prospective observational study examined whether brain MRI findings and previously reported risk factors for postoperative delirium were associated with delirium following OPCABG surgery. Our main finding was that 
Table 1 Patients' characteristics and intraoperative parameters $(n=88)$

\begin{tabular}{|c|c|}
\hline Age (yr) & $69(7)$ \\
\hline Height $(\mathrm{cm})$ & $162(8)$ \\
\hline Weight $(\mathrm{kg})$ & $63(11)$ \\
\hline Hypertension & $75(85 \%)$ \\
\hline Smoking & $11(13 \%)$ \\
\hline Diabetes mellitus & $47(53 \%)$ \\
\hline Hyperlimidemia & $65(74 \%)$ \\
\hline History of myocardial infarction & $29(33 \%)$ \\
\hline angina pectoris & $8(9 \%)$ \\
\hline heart failure & $10(11 \%)$ \\
\hline atrial fibrillation & $2(2 \%)$ \\
\hline cerebral infarction & $17(19 \%)$ \\
\hline Carotid artery stenosis $(>50 \%)$ & $20(23 \%)$ \\
\hline Operating time (min) & $290(56)$ \\
\hline Transfusion $(\mathrm{mL})$ & $1330(1316)$ \\
\hline Bleeding $(\mathrm{mL})$ & $1793(1325)$ \\
\hline Fluid administration $(\mathrm{mL})$ & $5069(1948)$ \\
\hline Urine output $(\mathrm{mL})$ & $1773(972)$ \\
\hline Lowest hemoglobin concentrations $\left(\mathrm{g} \cdot \mathrm{dl}^{-1}\right)$ & $8.6(0.9)$ \\
\hline \multicolumn{2}{|l|}{ Katz score* } \\
\hline I & $7(8 \%)$ \\
\hline II & $25(28 \%)$ \\
\hline III & $32(36 \%)$ \\
\hline IV & $19(22 \%)$ \\
\hline $\mathrm{V}$ & $2(2 \%)$ \\
\hline
\end{tabular}

Data represent mean (SD) or number (\%), as indicated

*Katz score, ${ }^{22}$

I: Normal to mild intimal thickening; II: Severe intimal thickening without protruding atheroma; III: Atheroma protruding $<5 \mathrm{~mm}$ into lumen; IV: Atheroma protruding $\geq 5 \mathrm{~mm}$ into lumen; V: Any thickness with mobile component or components

new ischemic lesions seen on MRI, carotid artery stenosis $>50 \%$, and DSWMH were independently associated with postoperative delirium. We also demonstrated a relation between delirium and myocardial infarction.

The incidence of new ischemic lesions detected by brain MRI in our study was $7.9 \%$. This contrasts with on-bypass cardiac surgery studies in which a high number of postoperative lesions were detected by MRI: $47 \%$ after valvular surgery ${ }^{26}$ and $30 \%$ after on-pump CABG. ${ }^{27}$ In a prior study of OPCAB, although the patient number was small $(n=13)$, no postoperative embolic ischemic events were observed. ${ }^{28}$ Thus, in comparison to reports of onpump cardiac surgery, the incidence of injuries related to brain embolism following OPCAB was relatively low. The difference in the rates of DWI-defined ischemic lesions between the on-bypass and off-bypass cases might be explained by the numbers of cerebral emboli that occurred. For example, Liu et al. also found that avoiding CPB
Table 2 Findings of brain magnetic resonance imaging $(n=88)$

\begin{tabular}{|c|c|}
\hline Intracranial artery lesion & $24(27 \%)$ \\
\hline ICA stenosis & $16(18 \%)$ \\
\hline ICA occlusion & $2(2 \%)$ \\
\hline M1 stenosis & $5(6 \%)$ \\
\hline M1 occlusion & $1(1 \%)$ \\
\hline A1 stenosis & $7(8 \%)$ \\
\hline Basilar artery stenosis & $1(1 \%)$ \\
\hline Basilar artery occlusion & $1(1 \%)$ \\
\hline Vertebral artery stenosis & $4(4 \%)$ \\
\hline Vertebral artery occlusion & $2(2 \%)$ \\
\hline \multicolumn{2}{|l|}{ Fazekas scale } \\
\hline \multicolumn{2}{|l|}{$\mathrm{PVH}$} \\
\hline grade 0 & $17(19 \%)$ \\
\hline grade 1 & $49(56 \%)$ \\
\hline grade 2 & $21(24 \%)$ \\
\hline grade 3 & $1(1 \%)$ \\
\hline \multicolumn{2}{|l|}{ DSWMH } \\
\hline grade 0 & $12(14 \%)$ \\
\hline grade 1 & $59(67 \%)$ \\
\hline grade 2 & $16(18 \%)$ \\
\hline grade 3 & $1(1 \%)$ \\
\hline $\mathrm{T} 2 *$ positive & $14(16 \%)$ \\
\hline History of cerebral infarction & $17(19 \%)$ \\
\hline New ischemic lesion in MRI & $7(8 \%)$ \\
\hline
\end{tabular}

during $\mathrm{CABG}$ decreased the number of postoperative cerebral microemboli measured with bilateral TCD ultrasonography. ${ }^{29}$

There are several mechanisms by which ischemic lesions could result in delirium. For example, in an animal study, cholesterol cerebral emboli altered the permeability of the blood-brain barrier, activated microglia, and caused cognitive dysfunction in rats. ${ }^{30}$ After microglia returned to their resting state, the rats recovered from the cognitive decline, suggesting that inflammation due to emboli may have influenced cognitive function. Neuroinflammation may also be associated with delirium. Proinflammatory cytokines have been shown to lead to synaptic and neuronal dysfunction and to subsequent neurobehavioural and cognitive symptoms that are characteristic of delirium. ${ }^{31}$ Although the incidence of embolic events was low, it is possible that emboli contributed to the postoperative delirium given that the theories regarding the pathogenesis of delirium neuronal aging, oxidative stress, neurotransmitter and 
Table 3 Univariate analysis of risk factors of postoperative delirium

\begin{tabular}{|c|c|c|c|c|c|c|}
\hline DRS & $\begin{array}{l}0 \\
(n=25)\end{array}$ & $\begin{array}{l}1-7 \\
(n=48)\end{array}$ & $\begin{array}{l}>8 \\
(n=7)\end{array}$ & Odds ratio & $95 \% \mathrm{CI}$ & $P$ value \\
\hline Age $>70$ & 8 & 23 & 6 & 2.98 & 1.17 to 7.59 & 0.022 \\
\hline $\mathrm{DM}$ & 8 & 12 & 1 & 0.63 & 0.23 to 1.70 & 0.361 \\
\hline HT & 8 & 10 & 2 & 0.68 & 0.25 to 1.86 & 0.452 \\
\hline Anemia & 1 & 1 & 1 & 2.24 & 0.21 to 24.28 & 0.509 \\
\hline HLP & 1 & 1 & 1 & 2.12 & 0.20 to 23.01 & 0.536 \\
\hline CKD & 1 & 7 & 1 & 2.45 & 0.57 to 10.50 & 0.227 \\
\hline COPD & 1 & 3 & 1 & 1.69 & 0.26 to 11.20 & 0.585 \\
\hline Smoking & 5 & 8 & 2 & 1.07 & 0.35 to 3.28 & 0.912 \\
\hline AMI & 3 & 21 & 2 & 2.83 & 1.04 to 7.71 & 0.042 \\
\hline $\mathrm{HF}$ & 1 & 8 & 0 & 1.66 & 0.40 to 6.88 & 0.485 \\
\hline $\mathrm{AF}$ & 0 & 2 & 0 & 2.24 & 0.12 to 40.60 & 0.586 \\
\hline Carotid AS & 2 & 14 & 2 & 2.87 & 0.93 to 8.87 & 0.067 \\
\hline Cerebral AS & 4 & 14 & 2 & 1.82 & 0.64 to 5.14 & 0.262 \\
\hline Operation time $>5 \mathrm{hr}$ & 17 & 31 & 5 & 0.967 & 0.38 to 2.44 & 0.944 \\
\hline Bleeding $>1500 \mathrm{~mL}$ & 12 & 24 & 4 & 1.173 & 0.49 to 2.82 & 0.721 \\
\hline Katz Score & & & & 1.26 & 0.83 to 1.92 & 0.283 \\
\hline I & 4 & 2 & 0 & & & \\
\hline II & 10 & 11 & 2 & & & \\
\hline III & 6 & 21 & 1 & & & \\
\hline IV & 3 & 13 & 3 & & & \\
\hline V & 2 & 0 & 0 & & & \\
\hline New lesions in MRI & 1 & 3 & 3 & 8.73 & 1.51 to 50.66 & 0.016 \\
\hline DSWMH & & & & 3.21 & 1.36 to 7.59 & 0.008 \\
\hline Grade 0 & 5 & 5 & 0 & & & \\
\hline Grade 1 & 18 & 34 & 3 & & & \\
\hline Grade 2,3 & 2 & 9 & 4 & & & \\
\hline $\mathrm{PVH}$ & & & & 2.65 & 1.34 to 5.26 & 0.005 \\
\hline Grade 0 & 9 & 6 & 1 & & & \\
\hline Grade 1 & 12 & 31 & 1 & & & \\
\hline Grade 2 & 4 & 10 & 5 & & & \\
\hline Grade 3 & 0 & 1 & 0 & & & \\
\hline
\end{tabular}

$\mathrm{DRS}=$ delirium rating scale $\mathrm{CI}=$ confidence interval $\mathrm{DM}=$ diabetes mellitus; $\mathrm{HT}=$ hypertension; $\mathrm{HPL}=$ hyper lipidemia; $\mathrm{CKD}=\mathrm{chronic}$ kidney disease; $\mathrm{COPD}=$ chronic obstructive pulmonary disease; $\mathrm{AMI}=$ acute myocardial infarction; $\mathrm{HF}=$ heart failure; $\mathrm{AF}=\mathrm{atrial}$ fibrillation; Carotid AS = carotid artery stenosis; Cerebral AS = cerebral artery stenosis; MRI = magnetic resonance imaging; DSWMH $=$ deep subcortical white matter hyper intensities; $\mathrm{PVH}=$ periventricular hyper- intensity. Odds ratio means between DRS $=0$ and $1-7 ; 1-7$ and $>8$

Table 4 Multivariate analysis of risk factors of postoperative delirium

\begin{tabular}{lcll}
\hline & Odds ratio & $95 \%$ CI & $P$ value \\
\hline New ischemic & & & \\
Lesion in MRI & 11.07 & 1.53 to 80.03 & 0.017 \\
Carotid AS & 7.06 & 1.59 to 31.13 & 0.010 \\
MI & 3.78 & 1.05 to 13.65 & 0.043 \\
DSWMH & 3.04 & 1.14 to 8.12 & 0.027 \\
\hline
\end{tabular}

$\mathrm{CI}=$ confidence interval; $\mathrm{MRI}=$ magnetic resonance imaging; Carotid $\mathrm{AS}=$ carotid artery stenosis; $\mathrm{MI}=$ myocardial infarction; $\mathrm{DSWMH}=$ deep subcortical white matter hyper intensities neuroendocrine dysfunction, network disconnectivity - are complementary rather than competing. ${ }^{32}$

The presence of carotid artery stenosis $>50 \%$ implies the presence of chronic cerebral hypoperfusion and systemic arteriosclerosis. Symptomatic carotid artery stenosis also plays an important role in other cerebrovascular diseases, such as stroke, cognitive impairment, and dementia. ${ }^{33,34}$ Carotid stenosis is also associated with white matter lesions. ${ }^{35}$ A recent study indicated that asymptomatic internal carotid atherosclerosis is associated with large white matter hyperintensities, low total brain volume, and poor neuropsychological performance. ${ }^{36}$ The patients in our 
Table 5 Relationship between delirium and duration of ICU and hospital stay

\begin{tabular}{|c|c|c|c|c|c|}
\hline ICU stay (hr) & \multicolumn{2}{|c|}{ Median } & $25 \%$ tile & $75 \%$ tile & $P$ value \\
\hline \multicolumn{6}{|l|}{ DRS } \\
\hline 0 & \multicolumn{2}{|l|}{22} & 19 & \multicolumn{2}{|l|}{42} \\
\hline $1-7$ & \multicolumn{2}{|l|}{43} & 22 & \multicolumn{2}{|l|}{89} \\
\hline $8>$ & \multicolumn{2}{|l|}{67} & 46 & 73 & 0.002 \\
\hline Hospital stay & & Median & $25 \%$ tile & $75 \%$ tile & $P$ value \\
\hline \multicolumn{6}{|l|}{ DRS } \\
\hline 0 & & 19 & 16 & 22 & \\
\hline $1-7$ & & 20 & 18 & 24 & \\
\hline $8>$ & & 21 & 20 & 25 & 0.078 \\
\hline
\end{tabular}

$\mathrm{DRS}=$ delirium rating scale; $\mathrm{ICU}=$ intensive care unit

study who had carotid stenosis $>50 \%$ were most likely asymptomatic because at our institute carotid endarterectomy and carotid artery stenting are prioritized over CABG in patients with symptomatic carotid stenosis. Our finding that both carotid artery stenosis and white matter lesions had a significant association with postoperative delirium is compatible with the findings of previous studies.

White matter lesions appear as hyperintensities on T2weighted MRI images. In the general population, the prevalence of white matter hyperintensities ranges from 11 to $21 \%$ in adults around $64 \mathrm{yr}$ of age to $94 \%$ at age 82 yr. ${ }^{37,38}$ Previous studies reported a significant association between white matter lesions and postoperative delirium. ${ }^{17,18}$ Hatano et al. retrospectively investigated whether white matter hyperintensities predicted delirium after cardiac surgery. ${ }^{17}$ Although the incidence of postoperative delirium might have been underestimated because of the nature of their retrospective chart review using the Diagnostic and Statistical Manual of Mental Disorder, Fourth Edition, severe DSWMH had a significant OR (OR 3.9, 95\% CI: 1.2 to $12.5 ; P=0.02$ ) in the multivariate logistic regression analysis. The population of the above study ${ }^{17}$ included patients with valve replacement or repair and with $\mathrm{OPCAB}$, making it difficult to determine whether the effects of CPB were significant. In contrast, our study enrolled only OPCAB patients, and delirium was prospectively assessed with the DRS-98, likely resulting in more accurate findings.

Although we used the DRS-98 in the ICU, the Confusion Assessment Method-ICU (CAM-ICU) is arguably used more commonly for screening and diagnosis of delirium. However, the CAM-ICU is a categorical assessment, and thus the incidence of postoperative delirium might be underestimated by missing patients with less severe manifestations of delirium. Indeed, we examined specific score ranges to ensure that symptoms of postoperative delirium were not overlooked.

This study has several limitations. First, the number of patients studied was smaller than that of our initially calculated sample size, thus weakening the study's statistical power. However, we obtained significant results that were compatible with those of previous studies. Second, the delirium assessment was performed only once, between six and $24 \mathrm{hr}$ after extubation. Because of its fluctuating nature, we might have missed some patients who manifested delirium after the one-time assessment. In our institute, most patients are transferred to the ward of the cardiac surgical division the day after surgery. As a result, we were able to evaluate delirium status only in the ICU. Thus, delirium may have been underestimated if it occurred after patients moved to the ward. The duration of the ICU stay, however, had a significant association with postoperative delirium, meaning that the one-time assessment may have had clinical significance. Third, there was uncertainty as to what happens with these white matter lesions over the long term, although white matter lesions could indirectly predict an increased risk of stroke, dementia, and mortality. ${ }^{19}$ Fourth, we made an assumption that emboli are the key etiologic factors in all the lesions described, but we do not have any objective measurement of emboli, such as with TCD ultrasonography. Thus, we cannot rule out hypoperfusion or inflammation playing a significant role in the lesions that we described.

In conclusion, in patients undergoing OPCAB surgery, carotid artery stenosis of $>50 \%$ and the presence of white matter lesions were significantly associated with postoperative delirium in the ICU. Although MRI detected a lower incidence of new ischemic lesions than were seen in prior on-pump CABG studies, they were significantly associated with postoperative delirium.

Conflicts of interest None declared.

Funding This study was funded by a starter grant from National Cerebral and Cardiovascular Centre. '[Grant number 22-5-20]'. Trial registry number: UMIN000003485.

\section{References}

1. Gottesman RF, Grega MA, Bailey MM, et al. Delirium after coronary artery bypass graft surgery and late mortality. Ann Neurol 2010; 67: 338-44.

2. Rudolph JL, Jones RN, Levkoff SE, et al. Derivation and validation of a preoperative prediction rule for delirium after cardiac surgery. Circulation 2009; 119: 229-36.

3. Robinson TN, Raeburn CD, Tran ZV, Angles EM, Brenner LA, Moss $M$. Postoperative delirium in the elderly: risk factors and outcomes. Ann Surg 2009; 249: 173-8.

4. Witlox J, Eurelings LS, de Jonghe JF, Kalisvaart KJ, Eikelenboom P, van Gool WA. Delirium in elderly patients and 
the risk of postdischarge mortality, institutionalization, and dementia: a meta-analysis. JAMA 2010; 304: 443-51.

5. Chaput AJ, Bryson GL. Postoperative delirium: risk factors and management: continuing professional development. Can J Anesth 2012; 59: 304-20.

6. Grocott HP, Yoshitani K. Neuroprotection during cardiac surgery. J Anesth 2007; 21: 367-77.

7. Houlind K, Kjeldsen BJ, Madsen SN, et al. On-pump versus offpump coronary artery bypass surgery in elderly patients: results from the Danish on-pump versus off-pump randomization study. Circulation 2012; 125: 2431-9.

8. Lamy A, Devereaux PJ, Prabhakaran D, et al. Off-pump or onpump coronary-artery bypass grafting at 30 days. N Engl J Med 2012; 366: 1489-97.

9. Shroyer AL, Grover FL, Hattler B, et al. On-pump versus offpump coronary-artery bypass surgery. N Engl J Med 2009; 361: 1827-37.

10. Bokeriia LA, Golukhova EZ, Polunina AG. Postoperative delirium in cardiac operations: microembolic load is an important factor. Ann Thorac Surg 2009; 88: 349-50; author reply 350-1.

11. Whitaker D, Motallebzadeh R. Intraoperative cerebral highintensity transient signals and postoperative cognitive function: a systematic review. Am J Surg 2009; 198: 295-7; author reply 254-5.

12. Rudolph JL, Babikian VL, Treanor P, et al. Microemboli are not associated with delirium after coronary artery bypass graft surgery. Perfusion 2009; 24: 409-15.

13. Miyazaki S, Yoshitani K, Miura N, et al. Risk factors of stroke and delirium after off-pump coronary artery bypass surgery. Interact Cardiovasc Thorac Surg 2011; 12: 379-83.

14. Abbott AL, Chambers BR, Stork JL, Levi CR, Bladin CF, Donnan $G A$. Embolic signals and prediction of ipsilateral stroke or transient ischemic attack in asymptomatic carotid stenosis: a multicenter prospective cohort study. Stroke 2005; 36: 1128-33.

15. Mackinnon AD, Aaslid R, Markus HS. Ambulatory transcranial Doppler cerebral embolic signal detection in symptomatic and asymptomatic carotid stenosis. Stroke 2005; 36: 1726-30.

16. Rudolph JL, Babikian VL, Birjiniuk $V$, et al. Atherosclerosis is associated with delirium after coronary artery bypass graft surgery. J Am Geriatr Soc 2005; 53: 462-6.

17. Hatano $Y$, Narumoto $J$, Shibata $K$, et al. White-matter hyperintensities predict delirium after cardiac surgery. Am J Geriatr Psychiatry 2013; 21: 938-45.

18. Shioiri A, Kurumaji A, Takeuchi T, Matsuda H, Arai H, Nishikawa T. White matter abnormalities as a risk factor for postoperative delirium revealed by diffusion tensor imaging. Am J Geriatr Psychiatry 2010; 18: 743-53.

19. Debette S, Markus HS. The clinical importance of white matter hyperintensities on brain magnetic resonance imaging: systematic review and meta-analysis. BMJ 2010; 341: c3666.

20. Fazekas F, Kleinert $R$, Offenbacher $H$, et al. Pathologic correlates of incidental MRI white matter signal hyperintensities. Neurology 1993; 43: 1683-9.

21. Streifler JY, Rosenberg $N$, Chetrit A, et al. Cerebrovascular events in patients with significant stenosis of the carotid artery are associated with hyperhomocysteinemia and platelet antigen-1 (Leu33Pro) polymorphism. Stroke 2001; 32: 2753-8.

22. Katz ES, Tunick PA, Rusinek $H$, Ribakove $G$, Spencer FC, Kronzon I. Protruding aortic atheromas predict stroke in elderly patients undergoing cardiopulmonary bypass: experience with intraoperative transesophageal echocardiography. J Am Coll Cardiol 1992; 20: 70-7.

23. Trzepacz PT, Mittal D, Torres $R$, Kanary K, Norton J, Jimerson $N$. Validation of the Delirium Rating Scale-revised-98: comparison with the delirium rating scale and the cognitive test for delirium. J Neuropsychiatry Clin Neurosci 2001; 13: 229-42.

24. Franco JG, Trzepacz PT, Mejia MA, Ochoa SB. Factor analysis of the Colombian translation of the Delirium Rating Scale (DRS), Revised-98. Psychosomatics 2009; 50: 255-62.

25. Akaike $H$. A new look at the statistical model identification. IEEE Trans Autom Control 1974; 19: 716-23.

26. Knipp SC, Matatko N, Schlamann M, et al. Small ischemic brain lesions after cardiac valve replacement detected by diffusionweighted magnetic resonance imaging: relation to neurocognitive function. Eur J Cardiothorac Surg 2005; 28: 88-96.

27. Restrepo L, Wityk RJ, Grega MA, et al. Diffusion- and perfusionweighted magnetic resonance imaging of the brain before and after coronary artery bypass grafting surgery. Stroke 2002; 33: 2909-15.

28. Djaiani G, Fedorko L, Cusimano RJ, et al. Off-pump coronary bypass surgery: risk of ischemic brain lesions in patients with atheromatous thoracic aorta. Can J Anesth 2006; 53: 795-801.

29. Liu YH, Wang DX, Li LH, et al. The effects of cardiopulmonary bypass on the number of cerebral microemboli and the incidence of cognitive dysfunction after coronary artery bypass graft surgery. Anesth Analg 2009; 109: 1013-22.

30. Rapp JH, Pan XM, Neumann M, Hong M, Hollenbeck K, Liu J. Microemboli composed of cholesterol crystals disrupt the bloodbrain barrier and reduce cognition. Stroke 2008; 39: 2354-61.

31. Cerejeira J, Firmino H, Vaz-Serra A, Mukaetova-Ladinska EB. The neuroinflammatory hypothesis of delirium. Acta Neuropathol 2010; 119: 737-54.

32. Maldonado JR. Neuropathogenesis of delirium: review of current etiologic theories and common pathways. Am J Geriatr Psychiatry 2013; 21: 1190-222.

33. Marshall RS, Festa JR, Cheung YK, et al. Cerebral hemodynamics and cognitive impairment: baseline data from the RECON trial. Neurology 2012; 78: 250-5.

34. Zheng S, Zhang $M$, Wang $X$, et al. Functional MRI study of working memory impairment in patients with symptomatic carotid artery disease. Biomed Res Int 2014; 2014: 327270.

35. Saba L, Sanfilippo $R$, Pascalis L, Montisci R, Mallarini G. Carotid artery abnormalities and leukoaraiosis in elderly patients: evaluation with MDCT. AJR Am J Roentgenol 2009; 192: W6370.

36. Romero JR, Beiser A, Seshadri S, et al. Carotid artery atherosclerosis, MRI indices of brain ischemia, aging, and cognitive impairment: the Framingham study. Stroke 2009; 40: 1590-6.

37. Garde E, Mortensen EL, Krabbe K, Rostrup E, Larsson HB. Relation between age-related decline in intelligence and cerebral white-matter hyperintensities in healthy octogenarians: a longitudinal study. Lancet 2000; 356: 628-34.

38. Stromholm T, Saether OD, Aadahl P, Nilsen G, Kvaerness J, Myhre $\mathrm{HO}$. Alterations in intracranial volume following crossclamping of the descending thoracic aorta in pigs-an experimental study using MRI. Eur J Vasc Endovasc Surg 1995; 10: 36-9. 